\title{
Monitoring and Management of Greenhouse Gas Emissions from Construction Equipment Using Wireless Sensors
}

\author{
Yong-Seon Lee ${ }^{1}$, Mirosław J. Skibniewski ${ }^{1}$, and Won-Suk Jang ${ }^{2}$ \\ ${ }^{1}$ Department of Civil and Environmental Engineering, University of Maryland College Park, MD USA \\ ${ }^{2}$ Building and Fire Research Laboratory, National Institute of Standards and Technology Gaithersburg, MD \\ USA
}

\begin{abstract}
The construction industry alone produced approximately $1.7 \%$ of total U.S. greenhouse gas (GHG) emissions in 2002. This is equivalent to 6 percent of the total U.S. industrial-related greenhouse gas emissions. GHG emissions from construction equipments on project sites are highly variable. Standardized method with accuracy and reliability is needed for measuring the GHG emissions from construction equipments. Thus, to comprehend this variation fully and the GHG commodity each construction sites, web-based GHG emissions monitoring system that uses the ZigBee wireless sensors operated by ambient power harvesting for measuring conveniently is needed. According to the results, consuming allocations of each project sites are analyzed. And based on the amount of GHG emissions measured like electricity rates, authorized institute is trading greenhouse gas, regarding the redundant and surplus allocations rates, between project sites. This system would be possible to systematically manage the greenhouse gas and to reduce it eventually. This paper represents the system architecture concept and process for this research.
\end{abstract}

Keywords: web-based system, greenhouse gas (GHG), construction equipment, wireless sensor, trading center

\section{Introduction}

The reduction in greenhouse gas emissions, which is partly responsible for global warming, has become a task for maintaining national benefits rather than being simply an environmental protection problem. The recognition of the air pollution problem has changed internationally, as the United Nations Framework Convention on Climate Change (UNFCCC) was adopted through the United Nations Conference on Environment and Development (UNCED) held in Rio de Janeiro in 1992. The terms of the agreement should be fulfilled even by enterprises in their business activities as well as in national matters. Thirty-three states and the District of Columbia in the U.S. regulate automobile emissions by requiring periodic inspections of registered vehicles to ensure that their emissions equipment is functioning properly. However, only one state (New York) and one municipality (New York City) monitor the emissions of heavy vehicles (Clean Diesel Technologies 2008). Fossil fuels used as the power sources by vehicles and machinery, such as those used in construction sites, are largely responsible for the global greenhouse gas problem. In most of existing environmental regulations on enterprise activities, however, certain environmental criteria are designated by the government for enterprises to follow. These methods have some problems in terms of effectiveness, as business people tend to avoid the regulations as much as possible rather than voluntarily observing them. Moreover, as regulations criteria were set without exactly considering the environment of the work site or the characteristics of individual machinery, the industrial circles resisted such criteria. As a result, the development of evaluation technology or measurement technology for air pollution has been delayed. To overcome these disadvantages, it is possible to provide flexibility to users and to further efficiently reduce air environment pollution by introducing the 'Emissions Trading' system of GHG to each construction site. Such systems are now attracting worldwide attention for all industries. By changing the regulations related to air pollution into a system that offers economic benefits and follows market logic. We can influence GHG emissions in construction as well.

To achieve this goal, the first thing to do is to exactly measure amount of greenhouse gases emitted by construction equipment of the construction site. A number of recent research studies have been conducted 
in order to investigate the GHG emissions from construction equipment working on project sites. Among them, Lewis et al. (2008) investigated the challenges to quantification of GHG emissions from nonroad construction equipments and described associated regulations and incentives for reducing emissions. Rasdorf et al. (2009) researched outline standard procedures for field data collection for construction equipments based on in-use measurement methods. These research studies, however, simply regard measurement and analysis of the greenhouse gas emitted from the construction machinery of the site. Therefore, this study focuses on the measurement of the amount of emissions of greenhouse gas during the duty cycle of heavy vehicles in real time by configuring wireless networks using ZigBee sensors to make accurate measurements of greenhouse gas emissions and then emissions trading of GHG. For convenient measurement, low-priced and stable measurement methods would be carried out through the energy harvesting technology, which can power the wireless sensors by employing vehicle's own vibrations as a source of energy. A more flexible management system will be realized by embodying the greenhouse gas exchange system between the construction sites using the web-based system based on the accurately measured data. Accordingly, it would be possible to systematically manage the greenhouse gas and to reduce air pollution eventually.

\section{Wireless sensor}

ZigBee is emerging network technology and a wireless communication standard capable of realizing the ubiquitous environment to satisfy requirements. As a superset of IEEE 802.15.4 standard, ZigBee supports the industrial network standards, so that many industrial applications including construction automation, structural health monitoring, and automated control and operation can benefit from the advantages of the technology.

Table 1. Property of the physical layer in IEEE 802.15.4 [ZigBee Alliance, 2005]

\begin{tabular}{c|c|c|c}
\hline Frequency band & $2.4 \mathrm{GHz}$ & $915 \mathrm{MHz}$ & $868 \mathrm{MHz}$ \\
\hline Number of channels & 16 & 10 & 1 \\
\hline Bandwidth $(\mathrm{kHz})$ & 5,000 & 2,000 & 600 \\
\hline Data rate $(\mathrm{kbps})$ & 250 & 40 & 20 \\
\hline Symbol rate (ksps) & 62.5 & 40 & 20 \\
\hline Modulation method & O-QPSK $^{*}$ & BPSK $^{* *}$ & BPSK \\
\hline Diffusion method & DSSS $^{* * *}$ & DSSS & DSSS \\
\hline Available regions & Worldwide $^{2}$ & USA & Europe \\
\hline \multicolumn{4}{c}{ O-QPSK $^{*}$ (Offset Quadrature Phase Shift Keying) } \\
BPSK $^{* *}$ (Binary Phase Shift Keying) \\
DSSS $^{* * *}$ (Direct Sequence Spread Spectrum)
\end{tabular}

The ZigBee specification has been released publicly in June 2005, and products supporting the ZigBee standard are widely available in the market. Specified frequency allocations and physical layer recommended by IEEE 802.15.4 is listed in Table 1. ZigBee specification takes advantage of the IEEE 802.15.4 wireless protocols as basic communications method, and expands on this with a robust mesh network, application profiles, interoperability and device description.

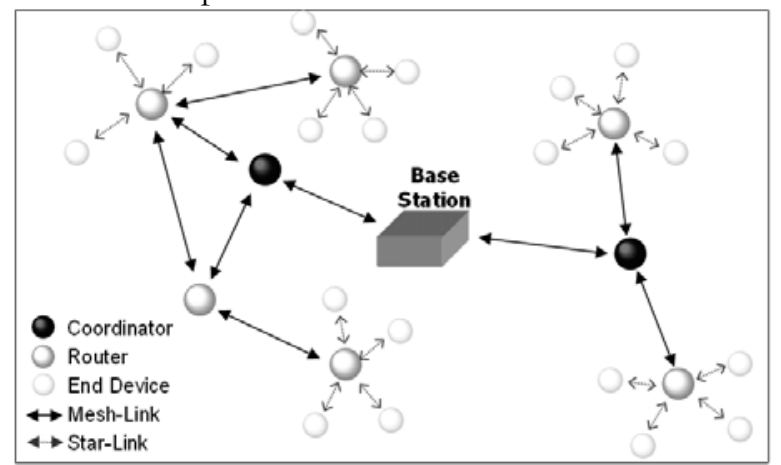

Figure 1. ZigBee Network [Skibniewski and Jang, 2006]. 
A ZigBee network, shown in Fig. 1, consists of ZigBee coordinators, ZigBee routers and ZigBee end devices [Skibniewski and Jang, 2006]. The coordinator and routers are able to form a star network configuration using PAN coordinator functions, and it is possible to form a multi-hop network by simultaneously configuring the mesh network between the coordinator and routers. The end devices take part in the network communication by linking to the coordinator and routers through star-link networks. The end devices conduct multi-hop communications via connected routers to communicate with other devices connected to the networks. Using the advantages associated with the flexible ad hoc networking, the promise of ZigBee application can be found in robust and reliable, self-configuring and self-healing networks that provide a simple, cost-effective and battery-efficient approach for sensing and network based data communication in construction industry.

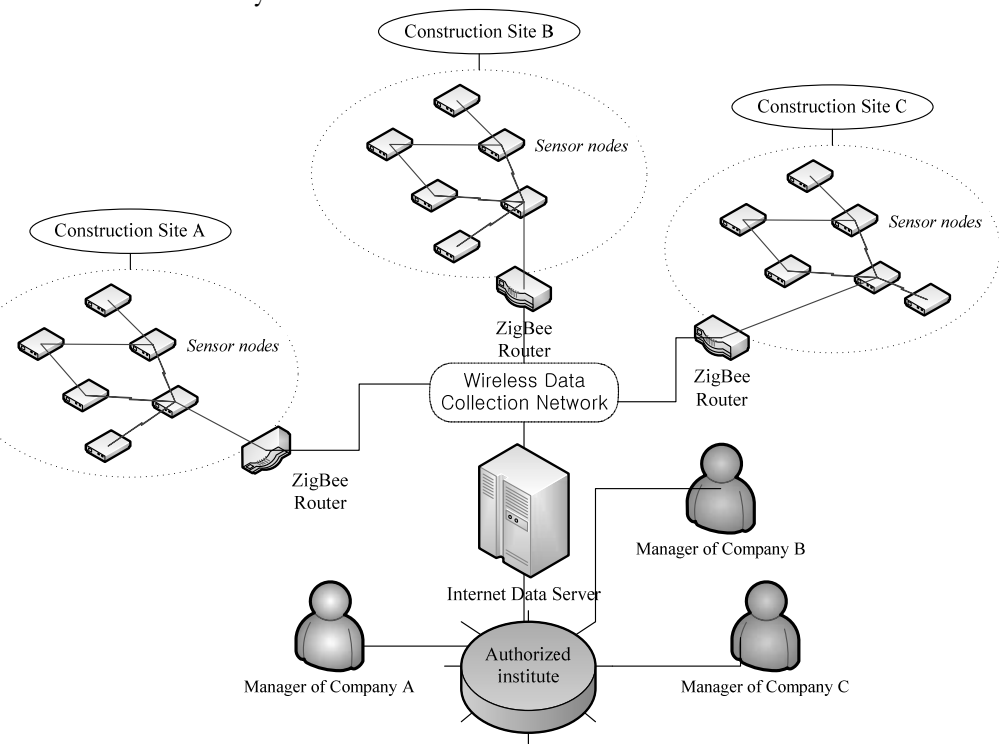

Figure 2. System composition of web-based system

In the wireless sensor network, ZigBee, elimination of undesirable multipath components and fading is an important issue to achieve the localization of the distributed objects. Coordinating is one of the most important tasks in wireless communication networks. To determine the paths and to advertise the identity of a sensor, different coordinating algorithms impose over communication overheads. The sensor nodes with ZigBee protocol transmit the radio signal within the maximum coverage range of $100 \mathrm{~m}$. And this specification of transmission determines the level of power and network topology to be communicated between sensor nodes and ZigBee router.

Using this wireless sensor network, system composition of web-based management system in construction site is made as shown in Fig. 2. ZigBee routers are placed at the location that can cover the entire laydown yard within their trigger ranges to detect the events associated with the movement of distributed sensor nodes. In this network system, measuring data collected to each of the routers is transmitted to the wireless collection network along with the ad hoc path. Different sensor nodes are categorized, identified, and attached to the construction equipments according to the characteristics of greenhouse gas property within the boundary of construction site. The collection network connects to the data server to be managed by authorized institute thorough the internet. The data of greenhouse gas can be used by companies registered through a user interface

\section{Energy harvesting for ZigBee sensor}

As shown in Fig. 3, when the distributed charge densities applied to the surface of the piezoelectric actuator are converted into voltages as in the following Eqn (1). The variation of the electric potential is obtained on the surface of the piezoelectric actuator; the electrical actuating vectors acting on each factor can be obtained by these actuating voltages (Elvin et al. 2006). 


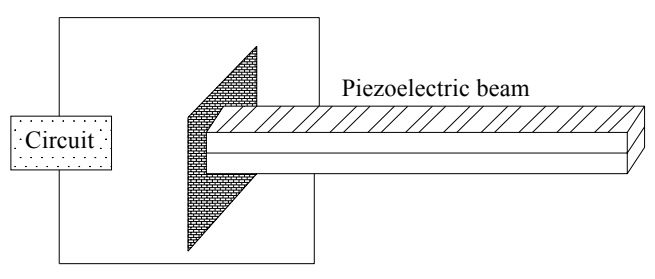

Figure 3. Piezoelectric beam

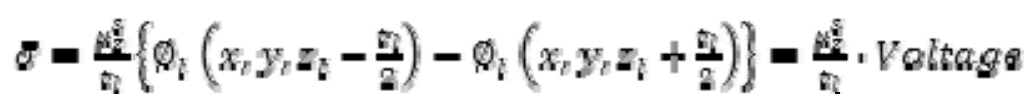

where $\emptyset_{\mathrm{l}}$ presents the $\oint_{\mathrm{l}}\left(\mathbf{x}_{v} \mathrm{y}_{r} \mathbf{z}\right)$ assumed as function of $\mathbf{x}_{r} \mathrm{y}_{z} \mathbf{z}$.

Moreover, the variation in electric potential on the surface of the piezoelectric actuator would be obtained by using the Eqn. (2) below.

$$
\begin{aligned}
& \delta \emptyset_{l}^{*}=\left.\left(z_{l}-z\right) \delta \emptyset_{l}^{\circ}(x)\right|_{z=z_{i}-\frac{5}{2}}=\frac{5}{2} \delta \emptyset_{l}^{\circ}(x) \\
& \delta \Phi_{l}^{b}=\left.\left(z_{l}-z\right) \delta \emptyset_{l}^{0}(x)\right|_{2=\alpha+\frac{\delta_{i}}{2}}=\frac{\Phi_{2}}{2} \delta \emptyset_{l}^{0}(x)
\end{aligned}
$$

where suffixes ' $\mathrm{t}$ ' and ' $\mathrm{b}$ ' show the top and bottom sides of the piezoelectric actuator fixed to the upper side of each beam. Thus, it is possible to configure the electrical actuating vectors expressed as terms of the actuating voltages.

As mentioned previously, this study uses wireless sensors using the energy harvesting technology. Thus, to analyze the validation whether the power of the wireless sensors themselves could be produced with the vehicle's own vibration, a 3-D model (Doyle 1991) of the moving construction vehicle was developed out as shown in Fig. 4. Likewise, the characteristic of road surface roughness in the construction site was randomly shown in Fig. 5 using a power spectral density function and the roughness coefficient of level poor (Dodds 1973). The equation of road roughness are expressed by choosing the phase angle randomly as in the following. $s$ is the distance $(V \cdot t)$.

$$
X(s)=\sum_{n=1}^{N} \sqrt{4 S_{X X}\left(\gamma_{n}\right) \Delta \gamma} \cos \left(2 \pi \gamma_{n} s-\theta_{n}\right)
$$

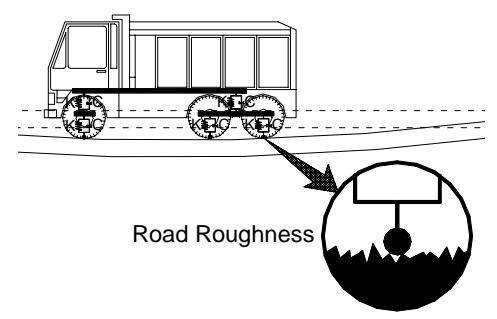

Figure 4. Analytical model

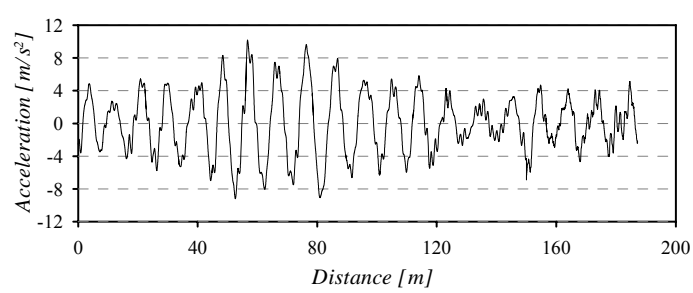

(a) acceleration calculated

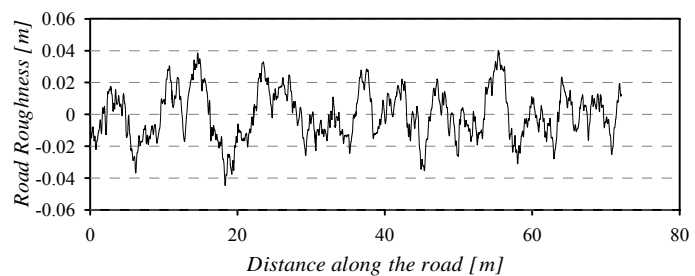

Figure 5. Road roughness

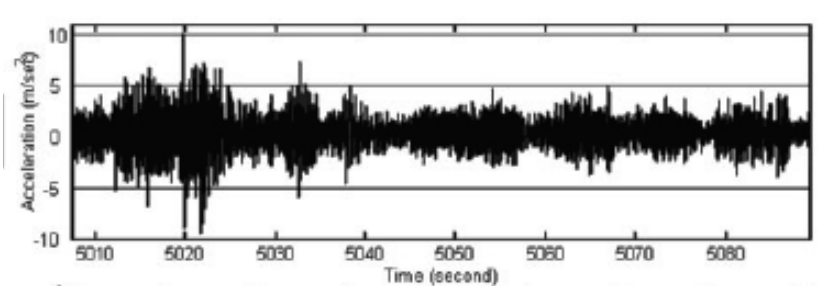

b) acceleration measured (Cho et al.2007)

Figure 6. Vehicle own responses 



Figure 7. Acceleration of concrete bridge

Figure 8. Scheme of energy harvesting

The acceleration response, which was produced from the moving vehicle on the randomly generated road surface roughness, was calculated and real acceleration was measured from heavy vehicle as shown in Fig. 6 . Figure 7 shows the acceleration generated by traffic loading on a concrete bridge. This response in Fig. 7 (Elvin et al. 2006) has enough magnitude that can be converted into electrical charge through the piezoelectric material. Therefore, the results were compared with an acceleration value of the vehicle, which was measured from the heavy vehicle running on the road. According to this comparison, it was analyzed that the vehicular vibration itself could be a sufficient energy source for energy harvesting. Figure 8 shows the scheme of energy harvesting using vehicle vibration.

\section{Measuring GHG emissions}

Currently the overall emission was calculated by determining the amount of GHG emitted from the fuels used as shown in the Eqn. (4). GHG emissions are estimated using the following equation (Mui, et al. 2007)

\section{Emtastons $=\left[\frac{\text { Gallome }}{\text { Shtie }}\right]\left[\begin{array}{c}\text { Garboun } \\ \text { Gallon }\end{array}\right]\left[\begin{array}{c}\text { Vehtcle Mtles } \\ \text { Traveled }\end{array}\right]$ $E=F^{\prime}\left(F^{\prime}\right.$ uel Consumption $) \times C($ Carbon Contowr $) \times A($ Actitity $)$}

Each of the three factors in the equation-per-mile fuel consumption $(\mathrm{F})$, fuel carbon content $(\mathrm{C})$ and VMT (vehicle-miles traveled) (A)-contributes to overall emissions. Thus, reductions in one parameter may be offset by increases in another. Comprehensive GHG policies will consider all three factors. In the other method, a simple equipment called portable emissions measurement systems (PEMS) was installed at the outlet of automobile exhaust fumes to measure the vehicle's emission amount of GHG. This method, however, cannot perform a long term calculation of the emission amount of GHG and have some restrictions on installation and operation under various environments due to problems such as equipment size, installation methods, and acquisition of power source. So, this method is being used mostly in laboratory measurement. To figure out these restrictions, this research tries to measure GHG from equipments used in the construction site by employing the wireless sensors. The testing procedure used in this study is shown in Fig. 9. First, the measurement ranges in each construction site was selected, and data, including various types of vehicles to be used in these construction site, working hours, and idle hours were preliminarily investigated and put in order. Next, main GHG emission sources of each construction area were determined, and these sources were measured to determine reference emission amounts per hour.

In addition, this study performs uncertainty interpretation of the measured GHG data. It analyzes the uncertainty of data caused by the deficiency of accuracy in the measurement values using the wireless sensors.

In the common case, a result, $\mathrm{R}$, to be function of $\mathrm{n}$ measured variables depends on measurements whose values are $x_{1} \pm w_{1}, x_{2} \pm w_{2}, \ldots ., x_{n} \pm w_{n}$.

$$
\tilde{N}=\tilde{f}\left(x_{1}, x_{2}, x_{2} \ldots \ldots, x_{n}\right)
$$

$w_{n}$ is the uncertainty in the variable. So maximum uncertainty in R can be estimated using the Eqn. (6). 


$$
W_{F_{i}}=\sqrt{\sum_{i=1}^{n}\left(w_{i} \frac{g_{i}}{g_{x}}\right)^{2}}
$$

This equation is known as square root mean of the sum of the squares (RSS). The confidence level in the result will be the same as the confidence levels of the uncertainties in the measured variables. Such an analysis can measure the GHG allocation amounts per scale of each construction site, and also calculate the exact measurement values to enable transactions between the construction sites.

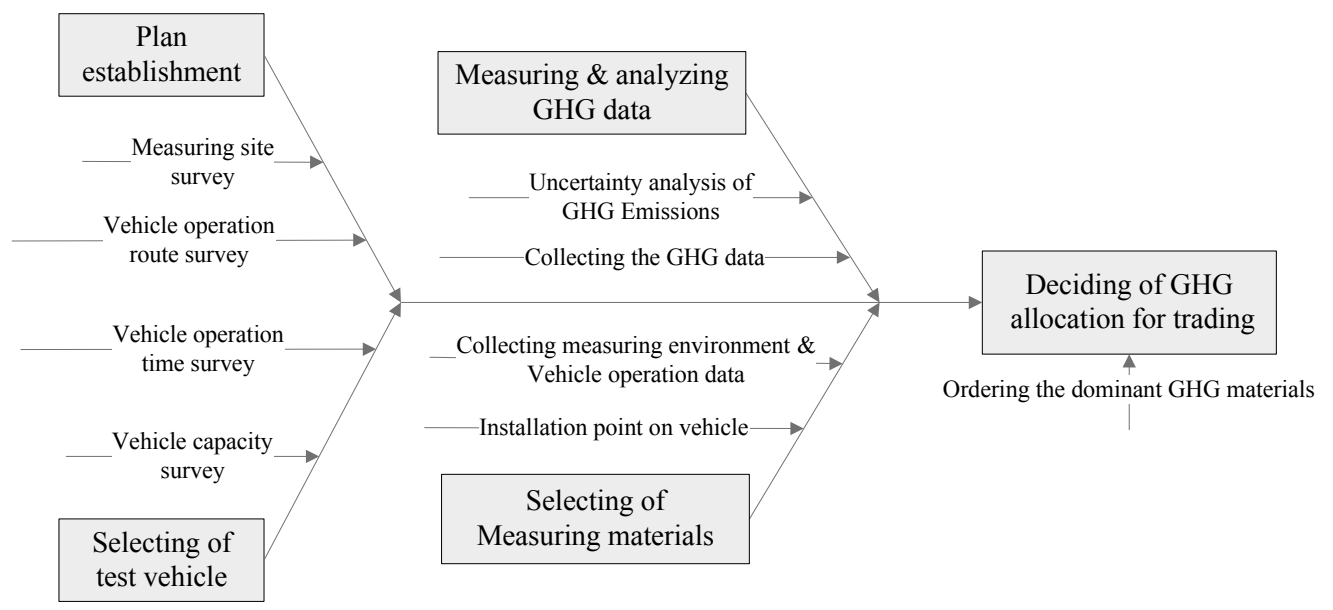

Figure 9. Experiment procedure

\section{Web-based GHG trading schemes for construction sites}

It is possible to determine the exact GHG emission amounts of construction equipment used in the construction site by using self-powered wireless sensors with the aforementioned piezoelectric material. Based on these exact emission amounts, an approved institution intermediates transactions between a construction site having surplus emission amounts of GHG and a construction site having excessive emission amounts. The intermediation method is to send the measurement values to the Internet, thereby constructing a web-based management system for managing these measurement values. The advantage of this a management system is the ability to check the emission amounts of GHG in real time in each construction area, and to enable one construction area, which needs additional allocations of GHG due to the excessive emission amounts, to confirm the allocations of another construction area that has surplus allocations and to immediately trade in with this construction area. Besides, the profits obtained through such a GHG trading system would be reinvested as research subsidies for the development of new energy sources, the construction of new generation plants, and repair and extension works of the degraded power plants. The flow of this trading system is shown in Fig. 10.

To establish this GHG trading, web-based management system need to develop approach system to be accessible data from the computer connected to the gateway as well as from anywhere. Software written in PHP to access the database and display results needs, therefore, to access the sensor database over the Internet. It lets the user modify the database to add more sensor nodes or sensor boards and allows him to query the database to find necessary data. The important parts of this web system include access to the data, information about each node in the network. The site with a familiar web environment allows the user to both read data that have been recorded and to modify the sensor network by adding descriptions of nodes or sensor boards.

Another function to be implemented in the website is the ability to change the information on the sensor network when nodes are moved to a different location and a specific node number is no longer needed, or when a new node is introduced into the network. Data are easily accessed via the website, and sensor nodes could be added to the network with little trouble. By breaking down the monitoring system into data 
acquisition, data storage, and data retrieval components, a flexible system is created that can be modified by users to meet their needs while allowing for advances in wireless sensing and networking technologies to augment monitoring capabilities without disrupting the operation of the entire system. The benefits of a system such as the one described in this work lie in the ease with which engineers can obtain information from construction equipment.

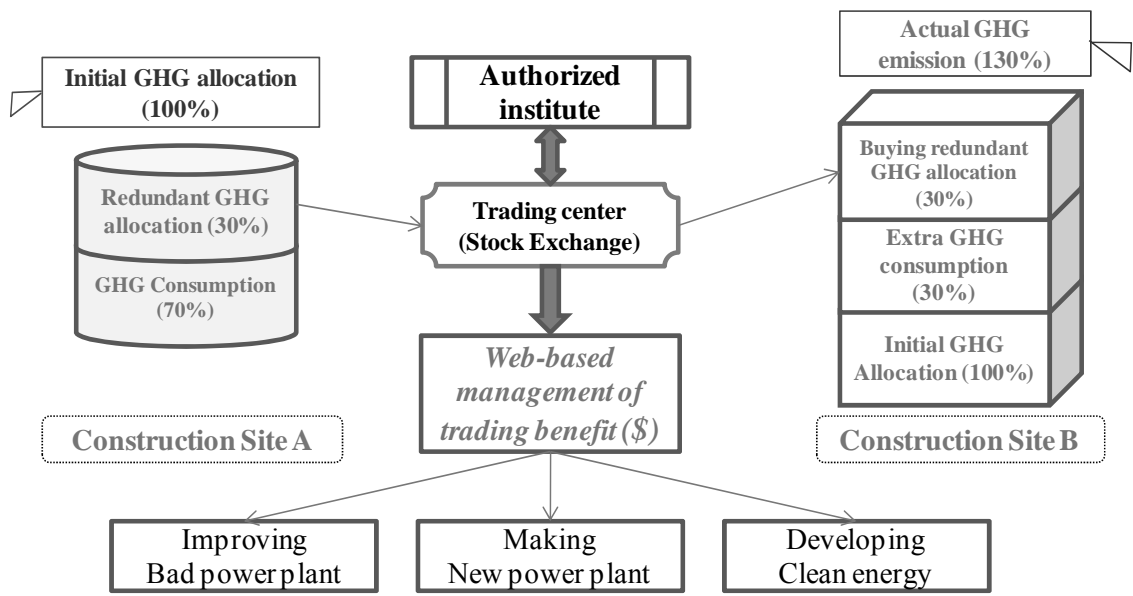

Figure 10. Diagram of web-based GHG trading

The committee of authorized institute would be responsible for sponsoring data integrity and reporting standards. Specifically, they would need to determine platform specific encryption standards and reporting pathways. Develop a select list of approved vendors for direct GHG monitoring and on-board computer interface systems. It would also be important for the committee to determine what information is important and how it should be analyze to help bolster the greenhouse gas emissions trading system. Furthermore, to enhance the reduction of greenhouse gases needs kinds of incentives. In a sense, it is necessary to design and implement a pathway for enhancing greenhouse gas trading of project sites with construction equipment within the international GHG emission trading framework.

\section{Conclusions}

This ongoing study aims to formulate a management solution for GHG trading between the construction sites based on the measured emission amounts. In order to analyze if vehicular vibration is sufficient to converts into a power source of the wireless sensors by using piezoelectric material, a vehicular response is compared with the substantial measurement value by considering the vehicular model and road surface condition of the construction field,. As a result, it was analyzed that the vehicular vibration was enough to be changed into the power source, which makes it possible to produce power using the vehicular vibration. Furthermore, the exact long term GHG emission amounts could be measured using the self-powered wireless sensors, and GHG trading between construction sites would be possible through the web-based management system on the basis of the exact measurement amounts of GHG. Likewise, the profits made by greenhouse gas trading would be invested for the improvement of degraded power plants, in the construction of new relatively "clean" plants with none to minimal GHG emission amounts, and the development of new clean energy. Accordingly, greenhouse gas emissions, which currently pose as a huge global problem, can be eventually reduced.

\section{References}

[1] Cho, B.H. and Lee, S.H. (2007). "Vibration performance of modular units under transportation." Journal of RIST Research, Research Institute of Industrial Science \& Technology, 21(3), 213-221.

[2] Clean Diesel Technologies. [Internet]. (2008). Clean Diesel Technologies Reduces Emissions for Skanska on New York City's Largest Public Works Project.

[3] Dodds, C.J. and Robson, J.D. (1973), “The Description of Road Surface Roughness.” Journal of Sound and Vibration, Elsevier, 31(12), 175-183. 
[4] Doyle, J.F. (1991). "Static and Dynamic Analysis of Structures: With an Emphasis on Mechanics and Computer Matrix Methods." Springer.

[5] Elvin, N.G., Lajnef, N., and Elvin, N.G. (2006). "Feasibility of structural monitoring with vibration powered sensors, Smart Materials and Structures.” Institute of Physics Publishing, 15, 977-986

[6] Lee, Y.-S., Kim, S.-H., and Jang, W.-S. (2005). "Analysis of Sound Radiation from the Coupling Effect of Vibrating Noise and Moving-Vehicles Noise on Bridges." Canadian Journal of Civil Engineering, NRC Research Press, 32(5), 881-898.

[7] Lewis, P., Rasdof, W., Frey, H.C., Pang, S.-H., and Kim, K. (2008). "Requirements and incentives for reducing construction vehicle emissions and comparison of non-road diesel engine emissions sources." Journal of Construction Engineering and Management, American Society of Civil Engineers, in press

[8] Mui, S., Alson, J., Ellies, B. and Gauss, D. (2007). "A Wedge Analysis of the U.S. Transportation Sector." Environmental Protection Agency. EPA 420-R-07-007, 23 pp.

[9] Rasdof, W. Frey, H.C., Lewis, P., Kim, K., and Pang, S-H., (2009). "Field Procedures for Real-World Measurement of Emissions from Diesel Construction Vehicles.” Journal of Infrastructure System, American Society of Civil Engineers, Submitted

[10] Skibniewski, M. J. and Jang, W.-S. 2006. "Ubiquitous computing: object tracking and monitoring in construction processes utilizing ZigBee networks." in Proc of International Symposium on Automation and Robotics in Construction 2006, ISARC 2006, 287-292.

[11] ZigBee Alliance. ZigBee specification. ZigBee Document 05347r06, San Ramon, CA, USA, June 27, 2005. 